\title{
Therapeutic implications of transesophageal echocardiography after transthoracic echocardiography on acute stroke patients
}

\author{
Tiago Tribolet de Abreu \\ Sonia Mateus \\ Cecilia Carreteiro \\ Jose Correia
}

Laboratorio de Ultrasonografia Cardiaca e Neurovascular, Hospital do Espirito Santo-Evora, E. P. E., Portugal
Correspondence:Tiago Tribolet de Abreu Rua Dr. Celestino David, no 32, 7000-852 Evora, Portugal Email ttabreu@clix.pt
Background: The role of transesophageal echocardiography (TEE) in the evaluation of acute stroke patients is still ill-defined. We conducted a prospective observational study to find the prevalence of TEE findings that indicate anticoagulation as beneficial, in acute ischemic stroke patients without indication for anticoagulation based on clinical, electrocardiographic and transthoracic echocardiography (TTE) findings.

Methods: We prospectively studied all patients referred to our laboratory for TTE and TEE. Patients were excluded if the diagnosis was not acute ischemic stroke or if they had an indication for anticoagulation based on clinical, electrocardiographic, or TTE data. Patients with TEE findings that might indicate anticoagulation as beneficial were identified.

Results: A total of 84 patients with acute ischemic stroke and without indication for anticoagulation based on clinical and electrocardiographic or TTE data were included in the study. Findings indicating anticoagulation as beneficial were found in $32.1 \%$ : spontaneous echo contrast (1.2\%), complex aortic atheroma $(27.4 \%)$, thrombus $(8.3 \%)$, and simultaneous patent foramen ovale and atrial septal aneurysm (2.4\%).

Conclusions: The results of our study show that TEE can have therapy implications in $32.1 \%$ of ischemic stroke patients in sinus rhythm and with TTE with no indication for anticoagulation.

Keywords: acute ischemic stroke, transesophageal echocardiography, transthoracic echocardiography, therapy

\section{Introduction}

The role of transesophageal echocardiography (TEE) in the evaluation of acute stroke patients is still ill-defined (Adams et al 2003; Hack et al 2003).

While some studies conclude that TEE should be mandatory on all ischemic stroke patients, based on its cost-effectiveness (McNamara et al 1997) and sensitivity for findings that change clinical management (coumadin instead of aspirin) (Blum et al 2004), others find that TEE abnormalities are found mostly in patients already with clinical, electrocardiographic or transthoracic echocardiography (TTE) data that would justify anticoagulation, and are rare in patients with sinus rhythm and with a normal TTE (Leung et al 1995; Cabral et al 2001; Agmom and Khandheria 2002). As a consequence, the usefulness of TEE findings for the clinical management of ischemic stroke patients has been challenged, but not defined, with some authors defending TEE only on patients with abnormal TTE (Leung et al 1995), with a normal TTE (Nighoghossian 1995), on an individual patient basis (Cabral et al 2001), or questioning its usefulness in the management of any ischemic stroke patient (Warner and Momah 1996). 
The aim of our study was to find the prevalence of TEE findings that indicate anticoagulation as beneficial, in acute ischemic stroke patients without indication for anticoagulation based on clinical, electrocardiographic, and TTE findings.

\section{Methods}

This was a prospective observational study, carried out from April 13, 2004 to October 11, 2005. The study was approved by our hospital ethics committee. Informed consent was obtained from all patients.

\section{Patients}

All patients referred to our laboratory simultaneously for TEE and TTE were enrolled in the study. Patients were excluded if the diagnosis was not acute ischemic stroke, or if they had an indication for anticoagulation based on clinical and electrocardiographic or TTE data.

The diagnosis of stroke was made by the referring physicians, based on clinical data and brain CT.

\section{Echography}

All the echographic studies were performed by the authors, on a Vivid 3 System, General Electric.

Transthoracic echocardiography was performed using a 2.5-MHz transducer for M-mode, 2D, and Doppler, according to the recommendations of the American Echocardiography Society (Henry et al 1980).

Transesophageal echocardiography was performed using a multiplane 3.5 to $6.5 \mathrm{MHz}$ probe, according to standard protocols (Seward et al 1988). The presence of the following potential sources of embolism was specifically examined: (a) left atrial spontaneous echo contrast and thrombus; (b) atheroma in the thoracic aorta; (c) patent foramen ovale and atrial septal aneurysm; and (d) others, including valvular vegetations and intracardiac masses. Left atrial spontaneous echo contrast was diagnosed by the presence of characteristic dynamic smokelike swirling echo in the left atrium or the atrial appendage, distinct from background white noise due to excessive gain (Black et al 1991). Left atrial thrombus was diagnosed by the presence of an echodense mass in the left atrium or the left atrial appendage, distinct from the endocardium and the pectinate muscles of the left atrial appendage (Beppu et al 1984). The presence of atheroma in the thoracic aorta was examined. Atheroma that were mobile, pedunculated, or protruding $\geq 5 \mathrm{~mm}$ into the lumen were classified as complex atheroma (Karalis et al 1985; Katz et al 1992). All other sessile atheroma $<5 \mathrm{~mm}$ in thickness were classified as simple atheroma. The interatrial septum was examined for patent foramen ovale, atrial septal defect, and atrial septal aneurysm. Color doppler, without and with Valsalva manoeuvre, and bubble contrast study with agitated saline, also without and with Valsalva manoeuvre, were performed in all patients to look for interatrial shunting. Bubbles appearing in the left atrium within three cardiac cycles or observed traversing the interatrial septum constituted a positive study for shunting. Atrial septal aneurysm was defined as a thin-walled area in the region of the fossa ovalis with a base of at least $1.5 \mathrm{~cm}$ and an excursion with the cardiac cycle of at least $1.5 \mathrm{~cm}$ (Hanley et al 1985). Care was taken to distinguish a true atrial septal aneurysm from a hypermobile interatrial septum.

\section{Indications for anticoagulation}

TTE findings that were considered to indicate anticoagulation as beneficial (Tribolet de Abreu et al 2005) were defined as: mitral valve stenosis with an enlarged $(>55 \mathrm{~mm})$ left atria, valve prosthesis, left ventricular systolic dysfunction (with an estimated ejection fraction $<35 \%$ ), dilated cardiopathy, previous myocardial infarction (with left ventricular wall dyskinesis), left atria or left ventricle masses.

TEE findings that were considered to indicate anticoagulation as beneficial were defined as: left atrial spontaneous echo contrast and thrombus (Blum et al 2004), complex aortic atheroma (Amarenco et al 1994; Jones et al 1995), simultaneous patent foramen ovale and atrial septal aneurysm (Mas et al 2001; Kizer et al 2005), thrombus on any heart chamber, valve, or the aorta.

\section{Statistical analysis}

The program Statistical Package for the Social Sciences version 12.0 for Windows was used as a database.

\section{Results}

During the study period, 143 patients were sent to our laboratory for both TTE and TEE. In addition to 28 repeated examinations, a total of 31 patients were excluded for nonstroke diagnosis and for indications of anticoagulation before the performance of transesophageal echocardiography (Figure 1), leaving 84 patients included in the study.

The baseline characteristics and risk factors of the study patients are shown in Table 1.

A total of 27 (32.1\%) patients had TEE findings that might indicate anticoagulation as beneficial (Table 2), three of which had more than one finding (left atrial spontaneous echo contrast and complex aortic atheroma [1 patient], thrombus in the aortic artery wall and complex aortic atheroma [2 patients]). 


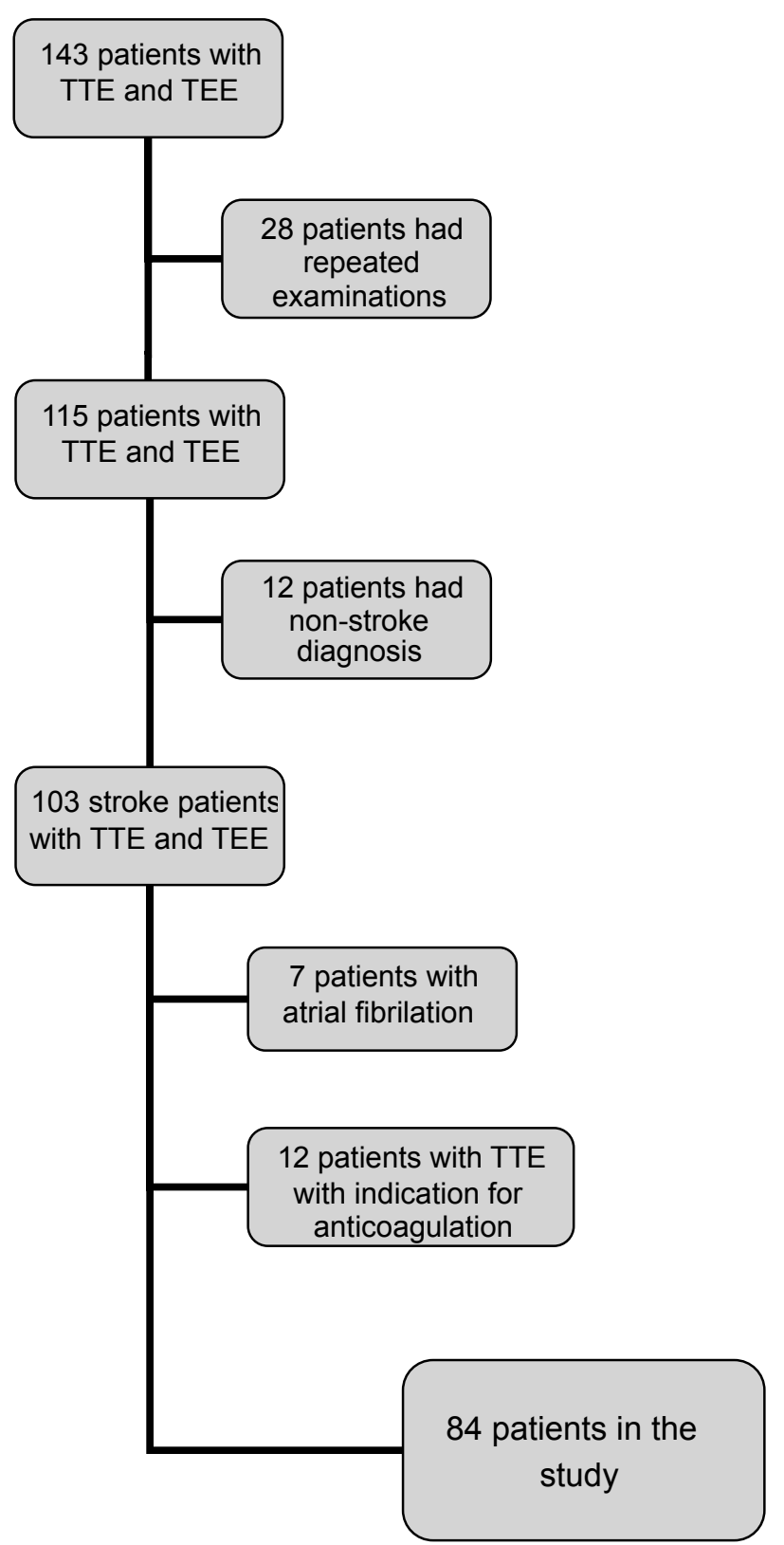

Figure I Diagram of patient enrollment.

Of the 7 patients with thrombus, 4 had thrombus in the aortic valve leaflets, and three patients had thrombus in the aortic artery wall.

\section{Discussion}

In our study, TEE had findings that might indicate anticoagulation as beneficial in $32.1 \%$ of our population of ischemic stroke patients, without other indications for anticoagulation by clinical, electrocardiographic or TTE data.

We found seven similar published studies (Leung et al 1995; Warner and Momah 1996; Palazzuoli 2000; Cabral et al 2001; Tatani 2001; Ward 2006; Harloff 2006;
Table I Baseline characteristics and risk factors of the study patients

\begin{tabular}{ll}
\hline Characteristic/risk factor & Study patients $(\mathbf{n}=\mathbf{8 4})$ \\
\hline Age, years (mean \pm SD) & $58 \pm 13$ \\
Male sex & $50(60 \%)$ \\
Hypertension & $57(68 \%)$ \\
Present smoking & $23(27 \%)$ \\
Hypercholesterolemia & $30(36 \%)$ \\
Diabetes mellitus & $17(20 \%)$ \\
\hline
\end{tabular}

Table 3). Only one of them was prospective (Harloff 2006), three included patients without a previous TTE (Warner and Momah 1996; Palazzuoli 2000; Tatani 2001), and two included patients with atrial fibrilation (Warner and Momah 1996; Harloff 2006). Only two of the studies specified the number of patients who had simultaneous patent foramen ovale and atrial septal aneurysm (Tatani 2001; Harloff 2006). This fact is relevant, since anticoagulation is considered beneficial only in patients with both these abnormalities (Mas et al 2001; Kizer et al 2005).

The most recent of these studies, by Harloff and colleagues (2006), was a prospective study in which TEE was performed on 503 out of 564 consecutive ischemic stroke patients, including patients excluded from our study, such as patients already with indications for anticoagulation, as atrial fibrilation and other types of cardioembolic stroke, and patients with contraindications against oral anticoagulation. They found spontaneous echo contrast in $11.5 \%$, complex aortic atheroma in $19.7 \%$, thrombus in $7.2 \%$ and simultaneous patent foramen ovale and atrial septal aneurysm in $9 \%$. They concluded that "TEE is indispensable in all patients being candidates for oral anticoagulation".

Our study patients were a selected group who were referred for TEE by the attending physician. During our study, a total of 855 patients were admitted to our hospital with a

Table 2 Transesophageal echocardiography findings indicating anticoagulation as beneficial

\begin{tabular}{ll}
\hline Finding & Number of patients (\%) \\
\hline Left atrial spontaneous echo contrast & $\mathrm{I}(\mathrm{I} .2 \%)$ \\
Thrombus & $7(8.3 \%)$ \\
Atrial septal aneurism & $10(11.9 \%)$ \\
Patent foramen ovale & $3(3.6 \%)$ \\
Simultaneous patent foramen ovale & $2(2.4 \%)$ \\
and atrial septal aneurysm & \\
Complex aortic atheroma & $23(27.4 \%)$ \\
Total patients with TEE findings indicating & $27(32.1 \%)$ \\
anticoagulation as beneficial & \\
\hline
\end{tabular}




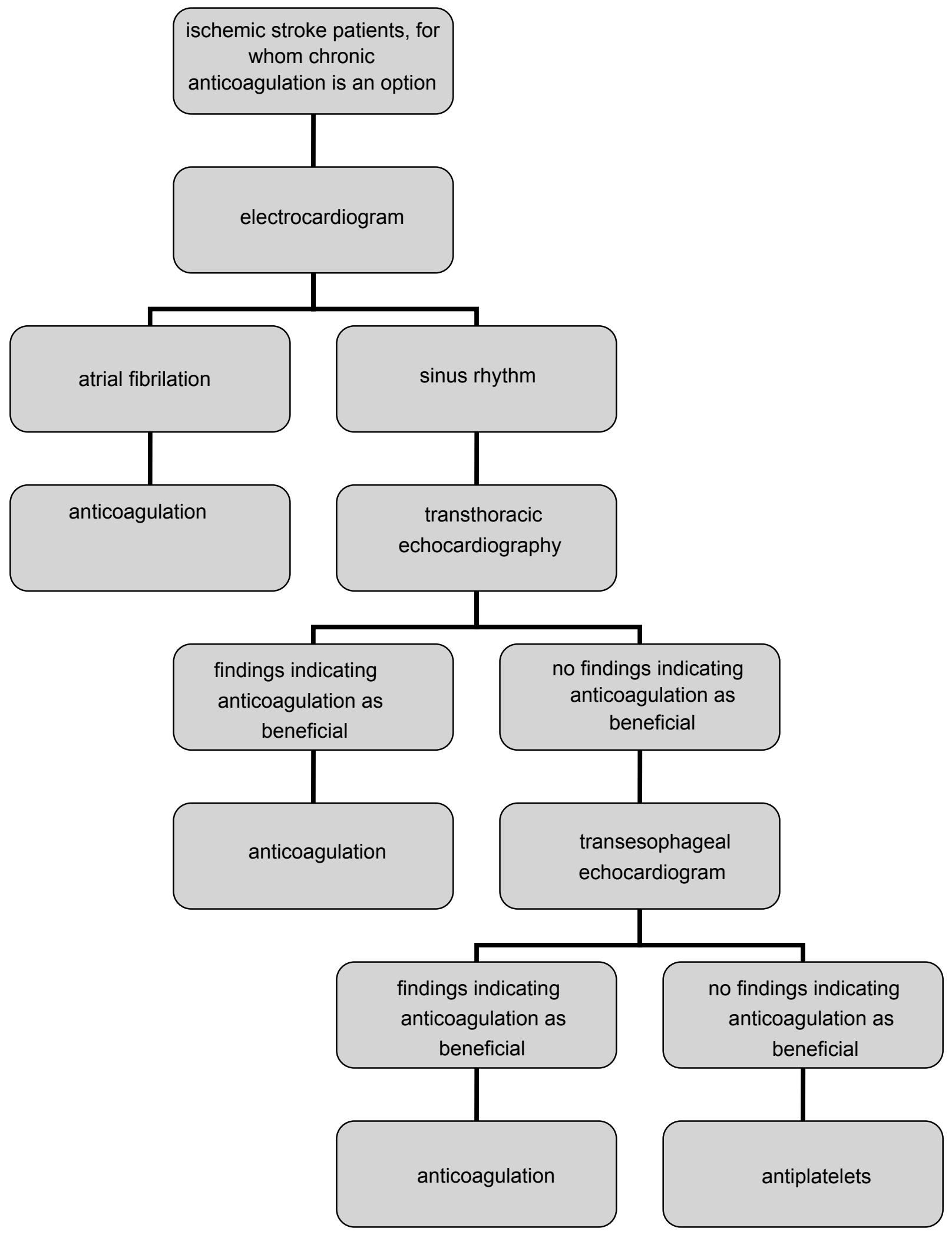

Figure 2 Proposed algorithm for the use of ultrasonographic studies on ischemic stroke patients. 
Table 3 Transesophageal findings in ischemic stroke patients

\begin{tabular}{|c|c|c|c|c|c|c|}
\hline Study & Patients & $\begin{array}{l}\text { Spontaneous } \\
\text { echo contrast }\end{array}$ & $\begin{array}{l}\text { Complex } \\
\text { aortic atheroma }\end{array}$ & Thrombus & $\begin{array}{l}\text { Inter atrial septum } \\
\text { abnormalities } \\
\text { (simultaneous } \\
\text { PFO/aneurism) }\end{array}$ & $\begin{array}{l}\text { Patients with } \\
\text { indication for } \\
\text { anticoagulation }\end{array}$ \\
\hline Leung et al 1995 & 236 & $1 \%$ & $4.6 \%$ & 0 & I8\% (not specified) & $5.6 \%$ \\
\hline Warner et al 1996 & $\begin{array}{l}106 \\
\text { (30 with atrial } \\
\text { fibrilation) }\end{array}$ & $12.3 \%$ & & $1.9 \%$ & & $35 \%$ \\
\hline Palazzuoli et al 2000 & 73 & $13 \%$ & $11 \%$ & $8 \%$ & 19\% (not specified) & $32 \%$ \\
\hline Cabral et al 200I & 172 & & $3.5 \%$ & $1.2 \%$ & $23 \%$ (not specified) & $4.7 \%$ \\
\hline Tatani et al 200I & 69 & $27.5 \%$ & $14.5 \%$ & $4.3 \%$ & $31.8 \%(5.8 \%)$ & $46.3 \%$ \\
\hline Ward et al 2006 & 245 & $3.7 \%$ & $14.7 \%$ & $2.4 \%$ & $22.1 \%$ (not specified) & $20.8 \%$ \\
\hline Harloff et al 2006 & $\begin{array}{l}503 \\
\text { (104 with atrial } \\
\text { fibrilation) }\end{array}$ & $11.5 \%$ & $19.7 \%$ & $7.2 \%$ & $26.2 \%(9 \%)$ & $30.6 \%$ \\
\hline Present study, 2007 & 84 & $1.2 \%$ & $27.4 \%$ & $8.3 \%$ & $(2.4 \%)$ & $32.1 \%$ \\
\hline
\end{tabular}

diagnosis of stroke (ischemic or hemorrhagic) or transient ischemic attack. Even if we consider $15 \%$ of these patients to have had an hemorrhagic stroke, the 143 patients in our study would represent approximately $20 \%$ of the remaining 727 patients. We cannot compensate for this bias.

Several TEE findings that might indicate anticoagulation as beneficial for secondary prophylaxis in ischemic stroke patients have been identified (Amarenco et al 1994; Jones et al 1995; Mas et al 2001; Blum et al 2004; Kizer et al 2005). The superiority of TEE over TTE for diagnosing these abnormalities has also been demonstrated (McNamara et al 1997; Blum et al 2004), and confirmed in our study. The prevalence of these abnormalities in a large unselected population of consecutive ischemic stroke patients has recently been studied by Harloff and colleagues (2006). Our results seem to confirm their findings, but on a more selected population of patients with no other indication for anticoagulation. Based on our study and on the study by Harloff and colleagues, we propose an algorithm for the use of ultrasonographic studies on ischemic stroke patients without contraindications for long term anticoagulation (Figure 2).

The results of our study show that TEE can have therapy implications in $32.1 \%$ of ischemic stroke patients in sinus rhythm and with a previous TTE with no indication for anticoagulation.

\section{References}

Adams HP Jr, Adams RJ, Brott T, et al. Stroke Council of the American Stroke Association. 2003. Guidelines for the early management of patients with ischemic stroke: a scientific statement from the Stroke Council of the American Stroke Association. Stroke, 34:1056-83.

Agmom Y, Khandheria BJ, Gentile F, et al. 2002. Clinical and echocardiographic characteristics of patients with left atrial thrombus and sinus rhythm. Circulation, 105:27-31.
Amarenco P, Cohen A, Tzourio C, et al. 1994. Atherosclerotic disease of the aortic arch and the risk of ischemic stroke. $N$ Engl J Med, 331:1474-9.

Beppu S, Park YD, Sakakibara H, et al. 1984. Clinical features of intracardiac thrombosis based on echocardiographic observation. Jpn Circ $J, 48: 75-82$

Black IW, Hopkins AP, Lee LC, et al. 1991. Left atrial spontaneous echo contrast: a clinical and echocardiographic analysis. J Am Coll Cardiol, 18:398-404.

Blum A, Reisner S, Farbstein Y. 2004. Transesophageal echocardiography vs. transthoracic echocardiography in assessing cardio-vascular sources of emboli in patients with acute ischemic stroke. Med Sci Monit, 10: CR521-3.

Cabral S, Oliveira F, Pereira S, et al. 2001. Transesophageal echocardiography in the assessment of patients presenting with ischemic cerebral events without previous evidence of a cardiac source of emboli. Rev Port Cardiol, 20:247-58.

Hack W, Kaste M, Bogousslavski J, et al.; European Stroke Initiative Executive Comittee and the EUSI Writing Comittee. 2003. European Stroke Initiative Recommendations for Stroke Management: update 2003. Cerebrovasc Dis, 16:311-37.

Hanley PC, Tajik AJ, Hynes JK, et al. 1985. Diagnosis and classification of atrial septal aneurism by two-dimensional echocardiography: report of 80 consecutive cases. J Am Coll Cardiol, 6:1370-82.

Harloff A, Handke M, Reinhard M, et al. 2006. Therapeutic strategies after examination by transesophageal echocardiography in 503 patients with ischemic stroke. Stroke, 37:859-64.

Henry WL, DeMaria A, Gramiak R, et al. 1980. Report of the American Echocardiography Society Committee on Nomenclature and Standards in Two-Dimensional Echocardiography. Circulation, 62:212-15.

Jones EF, Kalman JM, Calafiore P, et al. 1995. Proximal aortic atheroma: an independent risk factor for cerebral ischemia. Stroke, 26:218-24.

Karalis DG, Chandrasekaran K, Victor MF, et al. 1985. Recognition and embolic potential of intraaortic atherosclerotic debris. $J$ Am Coll Cardiol, 17:73-8.

Katz ES, Tunick PA, Rusinek H, et al. 1992. Protruding aortic atheromas predict stroke in elderly patients indergoing cardiopulmonary bypass: experience with intraoperative transesophageal echocardiography. J Am Coll Cardiol, 20:70-7.

Kizer JR, Devereux RB. 2005. Patent foramen ovale in young adults with unexplained stroke. $N$ Engl J Med, 353:2361-72.

Leung DY, Black IW, Cranney GB, et al. 1995. Selection of patients for transesophageal echocardiography after stroke and systemic embolic events: role of transthoracic echocardiography. Stroke, 26:1820-4. 
Mas J-L, Arquizan C, Lamy C, et al. 2001. Recurrent cerebrovascular events associated with patent foramen ovale, atrial septal aneurysm, or both. N Engl J Med, 345:1740-6.

McNamara RL, Lima JAC, Whelton PK, et al. 1997. Echocardiographic identification of cardiovascular sources of emboli to guide clinical management of stroke: a cost-effectiveness analysis. Ann Intern Med, 127:775-87.

Nighoghossian N, Perinetti M, Barthelet M, et al. 1995. Transesophageal echocardiography in patients less than 60 years of age without obvious cardiac souce of embolism. Neurol Res, 17:368-72.

Palazzuoli A, Ricci D, Lenzi C, et al. 2000. Transesophageal echocardiography for identifying potential cardiac sources of embolism in patients with stroke. Neurol Sci, 21:195-202.

Seward JB, Khandheria BK, Oh JK, et al. 1988. Transesophageal echocardiography: technique, anatomic correlations, implementation and clinical applications. Mayo Clin Proc, 63:649-80.
Tatani SB, Fukujima MM, Lima JAC, et al. 2001. Clinical impact of transesophageal echocardiography in patients with stroke without clinical evidence of cardiovascular sources of emboli. Arq Bras Cardiol, 76:458-61.

Tribolet de Abreu T, Mateus S, Correia J. 2005. Therapy implications of transthoracic echocardiography in acute ischemic stroke patients. Stroke, 36:1565-6.

Ward RP, Don CW, Furlong KT, et al. 2006. Predictors of long-term mortality in patients with ischemic stroke referred for transesophageal echocardiography. Stroke, 37:204-8.

Warner MF, Momah KI. 1996. Routine transesophageal echocardiography for cerebral ischemia. Is it really necessary? Arch Intern Med, 156:1719-23. 